logous for HSV types 1 and 2. J Clin Microbiol 2005;43: $2058-64$.

[8] Kaji M, Kusuhara T, Ayabe M, Hino H, Shoji H, Nagao T. Survey of herpes simplex virus infections of the central nervous system, including acute disseminated encephalomyelitis, in the Kyushu and Okinawa regions of Japan. Mult Scler 1996;2:83-7.

[9] Martin JR, Stoner GL, Webster HD. Lethal encephalitis and non-lethal multifocal central nervous system demyelination in herpes simplex virus type 2 infections in mice. $\mathrm{Br} \mathrm{J}$ Exp Pathol 1982;63:651-66.

[10] Kristensson K, Svennerholm B, Vahlne A, Nilheden E, Persson L, Lycke E. Virus-induced demyelination in her- pes simplex virus-infected mice. J Neurol Sci 1982;53: $205-16$.

[11] Azumagawa K, Suzuki S, Tanabe T, Wakamiya E, Kawamura N, Tamai H. Neopterin, biopterin, and nitric oxide concentrations in the cerebrospinal fluid of children with central nervous system infections. Brain Dev 2003;25: 200-2.

[12] Studahl M, Hagberg L, Rekabdar E, Bergstrom T. Herpes virus DNA detection in cerebral spinal fluid: differences in clinical presentation between alpha-, beta-, and gammaherpes viruses. Scand J Infect Dis 2000;32:237-48.

[13] Gobbi C, Tosi C, Stadler C, Merenda C, Bernasconi E. Recurrent myelitis associated with herpes simplex virus type 2. Eur Neurol 2001;46:215-8.

\title{
Acute pulmonary aspergillosis in immunocompetent subjects after exposure to bark chippings
}

\author{
MAIKEN CAVLING ARENDRUP ${ }^{1}$, B. RONAN O'DRISCOLL ${ }^{2}$, ESKILD PETERSEN $^{3}$ \& \\ DAVID W. DENNING ${ }^{4}$
}

From the ${ }^{1}$ Unit of Mycology and Parasitology, Statens Serum Institute, Copenhagen, Denmark, ${ }^{2}$ Hope Hospital, Salford, University of Manchester, UK, ${ }^{3}$ Department of Infectious Diseases, Aarhus University Hospital-Skejby, Aarhus, Denmark, and ${ }^{4}$ The University of Manchester and Wythenshawe Hospital, Southmoor Road, Manchester, UK

\begin{abstract}
We describe 2 cases of immunocompetent males with acute community-acquired invasive pulmonary aspergillosis developing shortly after spreading bark chippings. One patient with a fatal outcome was initially diagnosed as allergic alveolitis rather than infection and received steroid treatment illustrating the obvious challenges in the differential diagnosis between these disease entities.
\end{abstract}

\section{Introduction}

Community-acquired pneumonia is usually caused by bacteria, occasionally viruses and, in the AIDS era, the fungus Pneumocystis jiroveci (formerly carinii). While invasive pulmonary aspergillosis (IPA) commonly complicates neutropenia, transplantation and medical intensive care patients [1-3], it is rare among patients without underlying immune suppression. However, a few cases of pulmonary aspergillosis in healthy subjects after exposure to vegetal dust or mouldy hay have been described [4,5]. Like Mycobacterium tuberculosis and Coccidioides immitis, Aspergillus fumigatus is notable for causing pulmonary cavitation, either rapidly in resolving neutropenia [6] or more slowly in those with chronic cavitary pulmonary aspergillosis [7]. Unlike most other microorganisms, A. fumigatus is also a major allergen causing allergic bronchopulmonary aspergillosis (ABPA) which complicates asthma or cystic fibrosis and is treated with corticosteroids $[8,9]$.

Bilateral interstitial infiltrates and cavitation are uncommon radiographic features of communityacquired pneumonia. We here present 2 cases of invasive aspergillosis in immunocompentent patients illustrating the difficult discrimination between invasive infection and allergic alveolitis and the unusual presentation with acute-onset cavitating pneumonia. The cases were probably caused by a massive inhalation of Aspergillus conidia in bark chippings.

Correspondence: M. Cavling Arendrup, Unit of Mycology and Parasitology, Statens Serum Institute Building 43/214C, Artillerivej 5, DK-2300 Copenhagen S, Denmark. Tel: +45226327 85. Fax: +453268 81 80. E-mail: mad@ssi.dk 


\section{Case 1}

A 33-y-old male was admitted to hospital on 6 January 2004 with dry cough, shortness of breath and fever. His only previous illness had been implantation of a mechanical heart valve requiring long-term warfarin since 2000 . One month before admission the patient had received a truck-load of bark chippings at home. A week later he distributed some of the bark chippings and that evening felt ill and stayed in bed with fever for a few $\mathrm{d}$. A week later he distributed the remaining bark chippings - which were wet and slightly steaming and showed mould-spots on the bark. During the work he felt irritation in the airways and later the same $\mathrm{d}$ he ran a fever of $40^{\circ} \mathrm{C}$ and cough. Penicillin for $7 \mathrm{~d}$ was prescribed on 7 December followed by a 3-d course of azithromycin initiated on 22 December 2003.

At the time of admission, the patient presented with dry cough, dyspnoea, tachypnoea and fever $\left(39^{\circ} \mathrm{C}\right)$. Physical examination revealed slight basal crackles. Chest radiograph and high resolution computerized tomography scan of the thorax showed bilateral interstitial infiltrates (Figure 1a). Laboratory findings included a C-reactive protein of 780
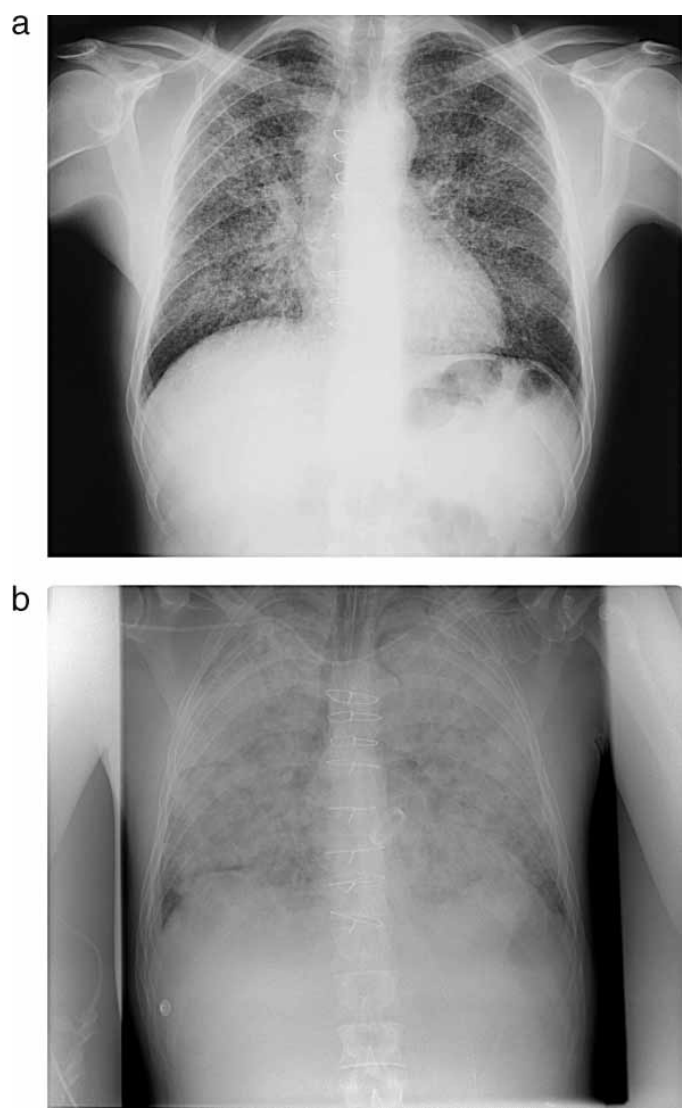

Figure 1. Chest radiograph a) at the time of admission (6 January) showing bilateral interstitial infiltrates, and b) dated 24 February showing severe progression of the bilateral infiltrates (Case 1). (normal range $<75$ ) nmol/l, negative blood cultures and Legionella urine antigen, PCR for Chlamydia pneumoniae and psittaci, Mycoplasma pneumoniae, Mycobacteria and Legionella, and negative microscopy and culture for Mycobacteria from sputum and BAL. Aspergillus antibody titre in serum taken 2 $\mathrm{d}$ after admission was 16 (normal range $<1$ ) and in BAL fluid on 15 January, lymphocytes were predominantly detected. Tentative diagnoses were atypical pneumonia and allergic alveolitis; clarithromycin and prednisolone $50-75 \mathrm{mg}$ daily were initiated and he was discharged on 28 January.

On 19 February the patient was re-admitted due to high fever (up to $40^{\circ} \mathrm{C}$ ), tachypnoea and cough. Chest radiograph showed bilateral infiltrates (Figure 1b). Laboratory findings were $10 \times 10^{9} / 1$ leukocytes, C-reactive protein of $3300 \mathrm{nmol} / \mathrm{l}$. A bronchial biopsy and culture was performed the next $d$ and histological examination demonstrated hyphae and inflammation. Culture yielded Aspergillus fumigatus. Ambisome $150 \mathrm{mg} / \mathrm{d}$ was given but the patient died on 28 February; autopsy revealed bilateral Aspergillus pneumonia (Figure 2) with involvement of the mediastinal lymph nodes and retroperitoneal bleeding. Subsequent testing of a serum sample dated 9 January showed an Aspergillus galactomannan antigen index of 5.1 (ref. $<1.0$ ).

\section{Case 2}

A 63-y-old gardener who smoked 20 cigarettes per d was admitted to hospital on 5 December 2003 with cavitating pneumonia of the right upper lobe (Figure 3a), associated with a 3-week history of dry cough, pleuritic pain and excessive sweating. His symptoms had not responded to a course of amoxicillin from his general practitioner. He had lost $3 \mathrm{~kg}$ in weight.

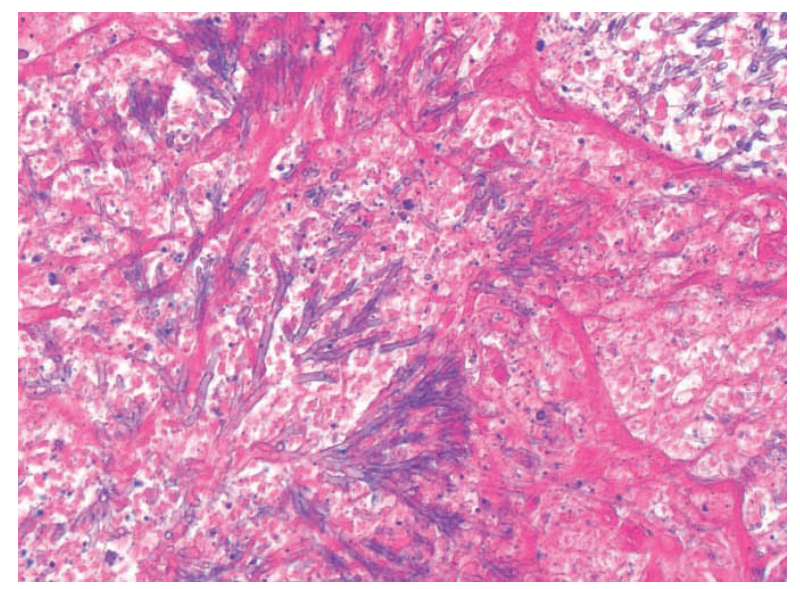

Figure 2. Histopathology of post mortem lung sections showing inflammation and microabcesses with dichotomously branching, septate hyphae (Case 1). (PAS staining, magnification $\times 200$ ). 

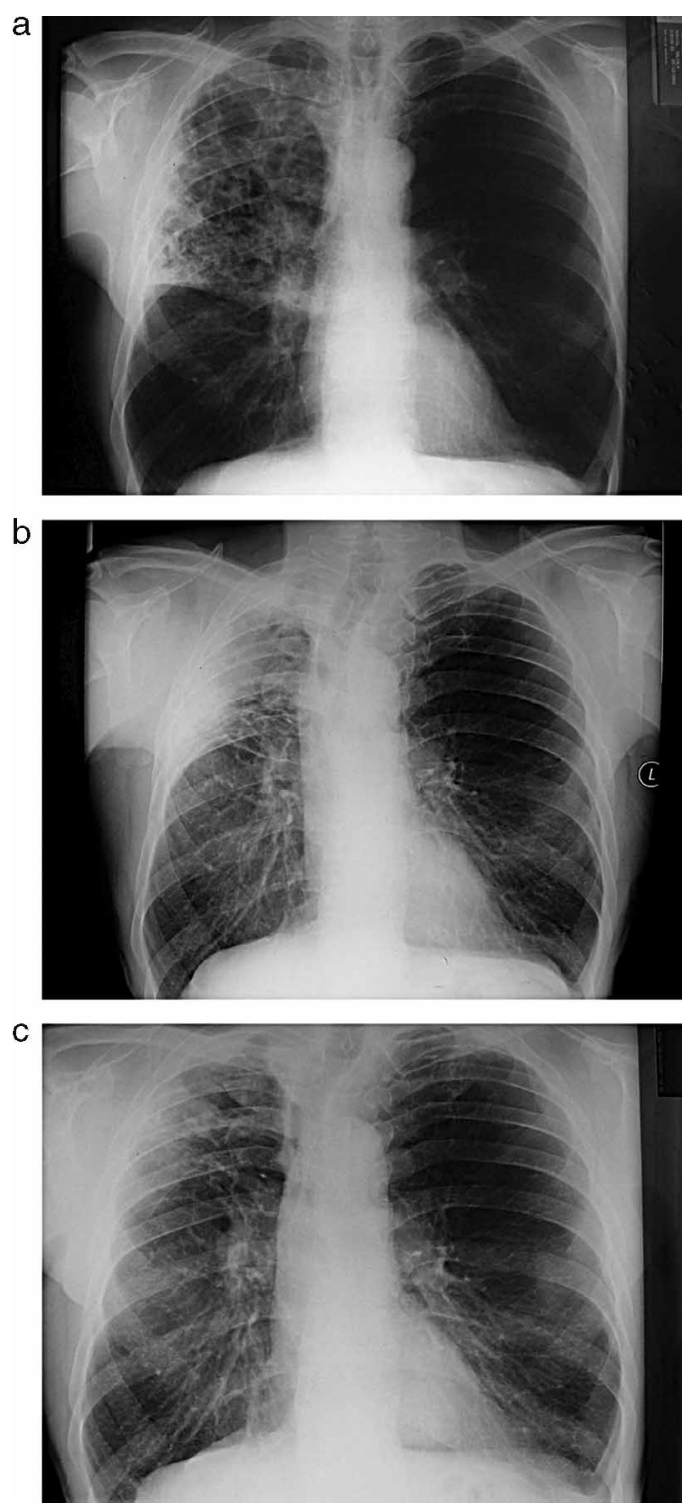

Figure 3. Chest radiographs a) at admission in December 2003 showing cavitating pneumonia of the right upper lobe, b) at follow-up in February 2004 showing shadowing and marked volume loss in the right upper lobe, and c) at follow-up $1.75 \mathrm{y}$ later in September 2005 showing further resolution (Case 2).

He had spread a large quantity of damp wood-bark chippings on the $\mathrm{d}$ before he developed his chest symptoms. Prior medical problems included a Barrett's oesophagus, mild airflow limitation (FEV1 $70-83 \%$ predicted), and early Dupuytrens contracture. On examination, his pulse was 96 and respiratory rate 14 and his temperature did not exceed $37.5^{\circ} \mathrm{C}$ at any time. Oxygen saturation was $92 \%$ breathing air and he had some soft crackles confined to the right upper lobe. CRP was extremely high at 378 units (normal below 10 units) and his ESR was elevated at $110 \mathrm{~mm} / \mathrm{h}$. His white cell count was elevated at $19.3 \times 10^{9} / 1$ (16.2 neutrophils).
Renal and liver function tests were normal apart from slightly elevated alkaline phosphatase at 152 units/1 (normal $<130$ units/l). Bronchoscopy was entirely normal and bronchial washings for culture and TB were negative but some 'yeasts' were seen on microscopy. Cytology showed mixed inflammatory cells and alveolar macrophages. He was treated with intravenous ceftriaxone and clarithromycin followed by oral levofloxacin and flucloxacillin and he was discharged on 12 December 2003.

He was seen in the outpatient clinic on 9 February 2004 and he continued to have excessive sweating and was coughing up about $30 \mathrm{ml}$ of white sputum without haemoptysis. He reported breathlessness at about $50 \mathrm{~m}$. On examination, his trachea had deviated to the right and the movement and the percussion note was diminished over the right upper lobe with increased breath sounds but no added sounds. His peak flow was $92 \%$ predicted at $450 \mathrm{l} / \mathrm{min}$ and spirometry was mildly obstructed. His chest radiograph at the clinic showed shadowing and marked volume loss in the right upper lobe (Figure 3b). His ESR remained elevated at $47 \mathrm{~mm} / \mathrm{h}$. A CT scan of his thorax showed considerable right upper lobe volume loss with fibrosis and cavitation. The largest cavity measured approximately $1.8 \mathrm{~cm}$ in diameter but no intracavitary mass was identified to suggest the presence of an aspergilloma. The extensive shadowing extended to the pleural space where there was associated pleural thickening. Background changes of small emphysematous bullae were noted. There was also mild right paratracheal nodule enlargement without a detectable bronchial tumour. His Aspergillus precipitin test was strongly positive (2 arcs) and anti-nuclear factor was positive $(1 / 1000)$. He was started on itraconazole $600 \mathrm{mg}$ daily for $4 \mathrm{~d}$, then itraconazole $400 \mathrm{mg}$ daily.

Two weeks after starting itraconazole therapy, the patient had improved substantially. His spirometry was stable at 2.3/3.7 and he remained breathless on walking about $50 \mathrm{~m}$. His general condition and spirometry gradually improved over the following 6 months. Spirometry was $2.6 / 3.7$ in July 2004 and 2.6/4.7 in November 2004. His weight was also better, inflammatory markers had improved (CRP and ESR fell to normal values and remained normal over 12 months) but his Aspergillus precipitin test remained positive at 2 arcs in July 2004, falling to 1 arc in January 2005. A control chest X-ray in September 2005 is shown in Figure 3c showing further resolution.

\section{Discussion}

In the cases described here, a massive $\mathrm{A}$. fumigatus inoculum from damp tree-bark chippings was prob- 
ably responsible for the infections - a relationship that to our knowledge has only once previously been described in a patient with chronic granulomatous disease [10]. It is known that $\mathrm{A}$. fumigatus is released into the air in large quantities when bark is stripped from trees [11]. This could be of considerable importance in the horticulture industry and the timber industry where this material is in widespread use. It is likely that workers with immunodeficiency or with ABPA would be at especially high risk but our patients had neither of these risk factors. The risk is probably magnified by dampness and subsequent mould growth.

The other feature of note in case 2 was the presence of an acute cavitating pneumonia. The differential diagnosis in community-acquired pneumonia would include staphylococcal, Klebsiella or Legionella infection or, with a subacute presentation, tuberculosis or coccidioidomycosis (if a history of travel to or residence in an endemic area). Both cases showed a failure to resolve promptly to antibiotic therapy, and this caused the clinicians to consider an Aspergillus-related problem. In the case with cavitation, the clinicians diagnosed Aspergillus infection and the patients improved on itraconazole therapy. However, only 2 of 12 cases of community-acquired invasive aspergillosis reviewed recently developed cavitating pneumonia; thus, cavitation appears to be an infrequent sign of this infrequent infection [12]. Case 1 had non-cavitating bilateral interstitial shadows with poor response to antibiotics, with a positive Aspergillus antibody test, which lead to the working clinical diagnosis of allergic alveolitis rather than infection. Meeker et al. described the development of hypersensitivity lung disease and invasive aspergillosis, respectively, in 2 siblings exposed to mouldy hay and an overlap between these 2 disease entities is possible [4].

Serological testing is used in the diagnosis of ABPA as well as invasive infection. Precipitating antibodies are typically present in ABPA and chronic cavitary pulmonary aspergillosis but not necessarily so during invasive infection of the immunosuppressed host [13]. On the other hand Aspergillus galactomannan antigen, a major component of the cell wall of Aspergillus, is detectable in the majority of cases of invasive pulmonary aspergillosis in those with underlying haematological disease and intensive care [14], and notably was also found in case 1 in high titre in a serum sample taken at the time of admission, consistent with (perhaps diagnostic of) invasive infection at this early time point. This suggests that the initial massive inhalation of spores lead directly to infection and not initially to an allergitic alveolitis which later progressed to invasive infection. The presence of antibody and antigen together is seen in some cases of invasive infection [15].

In the cases here described, the patients did not have any recognized underlying immune incompetence. Defects in mannose binding protein have been described in chronic cavitary pulmonary aspergillosis [16], and we cannot rule out that this or other subtle unrecognized immune defects were present in these patients.

While corticosteroids are the mainstay of treatment for ABPA and allergic alveolitis they increase the susceptibility to infection by Aspergillus fumigatus in 2 ways: 1) directly by decreasing oxidative killing by the macrophages; and 2) indirectly by enhancing the growth of the Aspergillus fungus itself [17-19]. Corticosteroids are a major risk factor for invasive aspergillosis $[20,21]$, and thus it is likely that the immunosuppression caused by the high-dose steroids and the late onset of antifungal treatment contributed to the fatal outcome in case 1 .

The cases here described illustrate the multifaceted nature of Aspergillus disease, and that the possibility of invasive infection should always be borne in mind also in non-neutropenic patients exposed to Aspergillus. The use of Aspergillus precipitating antibody and antigen testing early in community-acquired pneumonia could provide sufficient evidence for A. fumigatus infection to initiate treatment. A clinical history of excess mould or Aspergillus exposure (bark, vegetal dust, renovations etc.) may be a useful clinical clue, as may the radiographic appearance of cavitation and a lack of response to antibiotics.

Finally, it is advised that the manufacturers, distributors and end-users of tree-bark products need to be made aware of this potential hazard. People with known immuno-deficiency should be advised to avoid spreading tree-bark products and healthy people should be advised not to spread the product when it is wet and mouldy. We will notify the Health and Safety agencies in each of our countries of this hazard with a recommendation that the labelling of tree-bark products should be altered to alert consumers to the above hazards.

\section{Acknowledgements}

The authors wish to thank Sten Langfeldt, Department of Radiology and Steve Hamilton, Department of Pathology, Aarhus University Hospital, who kindly provided the digital images of the chest Xrays and the digital image of the lung section, respectively, from patient no. 1 . 


\section{References}

[1] Marr KA, Patterson T, Denning D. Aspergillosis. Pathogenesis, clinical manifestations, and therapy. Infect Dis Clin North Am 2002;6:875-94.

[2] Patterson TF, Kirkpatrick WR, White M, Hiemenz JW, Wingard JR, Dupont B, et al. Invasive aspergillosis. Disease spectrum, treatment practices, and outcomes. I3 Aspergillus Study Group. Medicine (Baltimore) 2000;79:250-60.

[3] Meersseman W, Vandecasteele SJ, Wilmer A, Verbeken E, Peetermans WE, Van WE. Invasive aspergillosis in critically ill patients without malignancy. Am J Respir Crit Care Med 2004; 170:621-5.

[4] Meeker DP, Gephardt GN, Cordasco EM Jr, Wiedemann HP. Hypersensitivity pneumonitis versus invasive pulmonary aspergillosis: 2 cases with unusual pathological findings and review of the literature. Am Rev Respir Dis 1991;143:431-6.

[5] Batard E, Renaudin K, Morin O, Desjars P, Germaud P. Fatal acute granulomatous pulmonary aspergillosis in a healthy subject after inhalation of vegetal dust. Eur J Clin Microbiol Infect Dis 2003;22:357-9.

[6] Denning DW. Invasive aspergillosis. Clin Infect Dis 1998;26: 781-803.

[7] Denning DW, Riniotis K, Dobrashian R, Sambatakou H. Chronic cavitary and fibrosing pulmonary and pleural aspergillosis: case series, proposed nomenclature change, and review. Clin Infect Dis 2003;37 (Suppl 3):S265-80.

[8] Stevens DA, Moss RB, Kurup VP, Knutsen AP, Greenberger $P$, Judson MA, et al. Allergic bronchopulmonary aspergillosis in cystic fibrosis: state of the art. Cystic Fibrosis Foundation Consensus Conference. Clin Infect Dis 2003;37 (Suppl 3): S225-64.

[9] Greenberger PA. Allergic bronchopulmonary aspergillosis. J Allergy Clin Immunol 2002;110:685-92.

[10] Zuk JA, King D, Zakhour HD, Delaney JC. Locally invasive pulmonary aspergillosis occurring in a gardener: an occupational hazard? Thorax 1989;44:678-9.

[11] Dutkiewicz J, Krysinska-Traczyk E, Prazmo Z, Skorska C, Sitkowska J. Exposure to airborne microorganisms in Polish sawmills. Ann Agric Environ Med 2001;8:71-80.
[12] Clancy CJ, Nguyen MH. Acute community-acquired pneumonia due to Aspergillus in presumably immunocompetent hosts: clues for recognition of a rare but fatal disease. Chest 1998;114:629-34.

[13] Yoshimoto A, Ichikawa Y, Waseda Y, Yasui M, Fujimura M, Hebisawa A, Nakao S. Chronic hypersensitivity pneumonitis caused by Aspergillus complicated with pulmonary aspergilloma. Intern Med 2004;43:982-5.

[14] Maertens J, Verhaegen J, Demuynck H, Brock P, Verhoef G, Vandenberghe $P$, et al. Autopsy-controlled prospective evaluation of serial screening for circulating galactomannan by a sandwich enzyme-linked immunosorbent assay for haematological patients at risk for invasive aspergillosis. J Clin Microbiol 1999;37:3223-8.

[15] Herbrecht R, Letscher-Bru V, Oprea C, Lioure B, Waller J, Campos $\mathrm{F}$, et al. Aspergillus galactomannan detection in the diagnosis of invasive aspergillosis in cancer patients. J Clin Oncol 2002;20:1898-906.

[16] Crosdale DJ, Poulton KV, Ollier WE, Thomson W, Denning DW. Mannose-binding lectin gene polymorphisms as a susceptibility factor for chronic necrotizing pulmonary aspergillosis. J Infect Dis 2001;184:653-6.

[17] Kan VL, Bennett JE. Lectin-like attachment sites on murine pulmonary alveolar macrophages bind Aspergillus fumigatus conidia. J Infect Dis 1988;158:407-14.

[18] Schaffner A. Therapeutic concentrations of glucocorticoids suppress the antimicrobial activity of human macrophages without impairing their responsiveness to gamma interferon. J Clin Invest 1985;76:1755-64.

[19] Ng TT, Robson GD, Denning DW. Hydrocortisoneenhanced growth of Aspergillus spp.: implications for pathogenesis. Microbiology 1994;140:2475-9.

[20] Balloy V, Huerre M, Latge JP, Chignard M. Differences in patterns of infection and inflammation for corticosteroid treatment and chemotherapy in experimental invasive pulmonary aspergillosis. Infect Immun 2005;73:494-503.

[21] Cornet M, Mallat H, Somme D, Guerot E, Kac G, Mainardi $\mathrm{JL}$, et al. Fulminant invasive pulmonary aspergillosis in immunocompetent patients: a 2-case report. Clin Microbiol Infect 2003;9:1224-7. 